\title{
Clinical Presentations of HHV-6 Infection in Infants and Children in Kuwait: A Retrospective Study
}

\author{
Nada Madi, Haya Al-Tawalah, Widad Al-Nakib \\ Virology Unit, Department of Microbiology, Faculty of Medicine, Kuwait University, Kuwait City, Kuwait \\ Email: madi@hsc.edu.kw
}

Received 23 September 2014; revised 31 October 2014; accepted 17 November 2014

Copyright (C) 2014 by authors and Scientific Research Publishing Inc.

This work is licensed under the Creative Commons Attribution International License (CC BY). http://creativecommons.org/licenses/by/4.0/

(c) (i) D Den Access

\begin{abstract}
Clinical manifestations of human herpesvirus 6 (HHV-6) have not been clearly defined, and the role of HHV-6 in human disease among infants and children in Kuwait remains to be fully elucidated. A retrospective study covering the period between 2008 and 2014 was conducted on infants and children aged from 1 month to 5 years. Blood and CSF samples from infants and children who presented with symptoms suggestive HHV-6 infection were subjected to PCR test for HHV-6. Results showed that $9.3 \%(n=42)$ of infants and children were positive for HHV-6. Fever was the most noticeable symptoms, presenting in $50 \%(n=21)$ of the patients. Also, neutropenia was highly associated with HHV-6 infection, where it presented in $35.8 \%(n=15)$ of infants and children. Our results provided important information about the clinical outcome of HHV-6 infection among infants and children in Kuwait.
\end{abstract}

\section{Keywords}

HHV-6, PCR, Kuwait

\section{Introduction}

Human herpesvirus 6 (HHV-6) is a ubiquitous virus, which is widespread thought the world. It belongs to the $\beta$-herpes group family to which cytomegalovirus (CMV) and HHV-7 are members [1]. Like other herpesviruses, it has the ability to remain latent and can be reactivated with immunosuppression [2]. Human herpesvirus infects approximately $70 \%$ of infants by the age of two years [3]. Primary infection causes undifferentiated febrile illnesses, where approximately $30 \%$ of children exhibit the classical clinical manifestations of exanthema subitum (also known as roseola infantum or sixth disease) [4] [5]. In addition, immunocompetant children may present 
with acute febrile illnesses with or without a rash [6]. Seizures are the most common complication of primary HHV-6 infection noted in approximately $14 \%$ of patients [7]. However, nonspecific symptoms without fever, such as fussiness and diarrhea, can occur after infection with the virus [8]. Other clinical manifestations include hepatitis, myocarditis, and encephalitis may also occur. This is with or without co-infection with other viruses [9] [10]. Following immunosuppression, HHV-6 can be reactivated and may result in severe neurological complications, such as multiple sclerosis, mesial temporal sclerosis and encephalitis [11]-[13].

From a study by Hussain et al. [14], where they investigated the infectious etiologies of neutropenia among children in Kuwait, there has been no published data on the spectrum of signs and symptoms developed as a result of HHV-6 infection in infants and children in Kuwait. Therefore, this study describes the clinical manifestations and syndromes associated with HHV-6 infection among infants and children in Kuwait.

\section{Methods}

\subsection{Patients}

This is a retrospective study covering the period between January 2008 and May 2014 on patients in different Hospitals in Kuwait including Mubarak, Amiri, Sabah, Adan, Farwania Hospital. The Organ Transplant Center (OTC) and Kuwait Cancer Control Center (KCCC) were also included in this study. Patients suspected of possible HHV-6 infection were investigated by PCR test, which was performed in the Virology Unit, Faculty of Medicine, Kuwait University. The samples were taken from 449 infants and children aged from 1 month to 5 years who presented with symptoms suggestive HHV-6 infection such as fever, roseola, and seizures and were hospitalized during the study period. Of these infants and children, 251 were males and 198 were females, with a mean age of 1.3 months. Among these patients, 212 were Kuwaiti and 237 were non-Kuwaiti. Clinical data for infants and children with positive results were retrospectively registered. This retrospective study based on patient referral with no disclosure of names and this study was approved by the ethical committee at the Faculty of Medicine, Kuwait University.

\subsection{Conventional PCR Assay and Definitions}

HHV-6 DNA was extracted from clinical samples (blood, CSF) using Roche ${ }^{\circledR} M a g N A$ Pure LC system (Roche Diagnostics, Indianapolis, IN, USA) according to the manufacturer's instructions. HHV-6 DNA in the clinical samples was detected by amplifying the conserved region in HHV-6A (U1102) and HHV-6B (Z29) by nested PCR. The first PCR reaction was performed using primers HHV (6-1) (F): 5'AAGCTTGCACAATGCCAAAAAACAG-3' and HHV (6-2) (R): 5'CTCGAGTATGCCGAGACCCCTAATC-3'. Ten $\mu$ of the extracted DNA was mixed with $15 \mu \mathrm{l}$ PCR mix that consisted of $12.5 \mu \mathrm{l}$ AmpliTaq Gold PCR Master Mix (Applied Biosystem, Branchburg, New Jersey, USA), $0.5 \mu \mathrm{l}$ of each primer (10 pmol) (Roche, Applied Biosystem, USA), and $1.5 \mu 1 \mathrm{H}_{2} \mathrm{O}$. The positive control was ATCC (American Type Culture Collection) strain of HHV-6. A total of 30 amplification cycles (each cycle consisted of $94^{\circ} \mathrm{C}$ for $1 \mathrm{~min}, 55^{\circ} \mathrm{C}$ for $1 \mathrm{~min}$, and $72^{\circ} \mathrm{C}$ for $1 \mathrm{~min}$ ) were carried out to amplify the target DNA. Second PCR reaction was performed using primers HHV (6-3) (F): 5'-TCCATTATTTTGGCCGCATTCGT-3' and HHV (6-4) (R): 5'-TGTTAGGATATACCGATGTGCGT-3'. One $\mu$ of the amplified product was mixed with $24 \mu \mathrm{l}$ PCR mix which consisted of $12.5 \mu \mathrm{l}$ AmpliTaq Gold PCR Master Mix, $0.5 \mu \mathrm{l}$ of each primer ( $10 \mathrm{pmol})$, and $10.5 \mu \mathrm{l}$ of $\mathrm{H}_{2} \mathrm{O}$. Thermal cycling condition was similar to the first PCR. The $173 \mathrm{bp}$ amplification products were visualized by QIAxcel System (Qiagen, Hilden, Germany) according to manufacturer's instructions.

DNAemia was defined as the presence of a positive HHV-6 DNA in blood or plasma. In addition, it has been previously determined that the detection of HHV-6 DNA in plasma is consistent with active infection [15]. Thus, active HHV-6 infection was defined as a positive plasma HHV-6 DNA PCR.

\subsection{Detection of Other Viruses}

Detection of IgM antibodies to Epstein Bar virus (EBV) in blood was performed using Trinty Biotech Captia Qualitative ELISA Kit (Trinty Biotech Plc, Bray, Co., Wicklow, Ireland) according to the manufacturer's instructions. Also, detection of IgM antibodies to Parvovirus B19 in blood was performed using Biotrin ELISA Kit (Biotrin Blackrock Co. Dublin, Ireland) according to the manufacturer's instructions. IgM antibodies to Adenovirus were detected in blood using NovaLisa Qualitative ELISA Kit (Nova Tech Immundiagnostica 
GmbH-Technologie \& Wald Park, Dietzenbach, Germany) according to the manufacturer's instructions. Enteroviruse RNA was detected by conventional PCR using QIAGEN One step RT-PCR Kit (Qiagen, Hilden, Germany) as described previously [16]. CMV DNA was detected by ArtusCMV PCR Kit (Qiagen, Hilden, Germany) using ABI PRISM 7500 Fast Real-Time PCR System. HSV DNA detection was performed using LightCycler HSV 1/2 Detection Kit (Roche Molecular Systems Inc., Branchburg, USA).

\section{Results}

HHV-6 infection was verified in $42 / 449(9.3 \%)$ infants and children. Of the positive infants and children, there were 24 male and 18 female with a male to female ratio of 1.3:1.

Among the 42 cases, the breakdown of positive HHV-6 DNA PCR results according to the sources of samples was as follows: $35(83.3 \%)$ were positive in plasma and $8(19 \%)$ were positive in CSF (Table 1). According to the definition of active infection (positive plasma PCR test), $83.3 \%$ had active infection. On the other hand, 8 patients (19\%) were PCR positive in CSF only (Table 1). Only one patient was positive in both CSF and plasma samples. However, one patient was CSF positive and plasma negative, which suggest that this patient had latent infection.

The clinical manifestations and syndromes of the 42 HHV- 6 positive infants and children are presented in Table 2. Fever was the most prominent finding, presented in 50\% $(n=21)$ of the HHV-6 cases. Roseolainfantum presented in $19 \%(\mathrm{n}=8)$ of the cases. The rash was maculopapular and most frequently generalized, involving face, trunk, and limbs. Seizure and vomiting were seen in $7.1 \%(\mathrm{n}=3)$ and $4.8 \%(\mathrm{n}=2)$ of the cases, respectively. In addition, Diarrhea, cough, otitis media, (2.4\% each) were less frequently seen in the HHV-6 cases. Fifteen children (35.8\%) had neutropenia at the time of hospitalization. Another three children (7.1\%) had meningitis. Encephalitis, thrombocytopenia, urinary tract infection (UTI), Bicytopenia, neonatal sepsis with shock, were seen in $2.4 \%$. Of the patients, one child had bone marrow transplantation with severe combined immunodeficiency syndrome (SCID) with MHC class II deficiency and had graft versus host disease. This child presented with severe rash.

The relationship between the presence of HHV-6 DNA and other viruses was also examined. Six children showed HHV-6 co-infection with other viruses (Table 3). Three children were positive for Enterovirus RNA, 2 children were positive for Parvovirus B19 positive, and two children were positive for EBV. In addition, one child was positive for Adenovirus and another one was positive for CMV.

\section{Discussion}

Infants and children aged from 1 month to 5 years were admitted to different hospitals in Kuwait based on clinical presentations suggestive of HHV-6 infection. These clinical presentations included high fever, seizures and rash. Blood samples were taken from these children in addition to CSF sample in cases of febrile convulsion or meningitis. The clinical samples were investigated for HHV-6 by PCR test in addition to other viruses. Results showed that HHV-6 infection was found in 42 (9.3\%) of infants and children. Male to female ratio was 1.3:1. This result was consistent with other studies reporting a predominance of male infants and children with HHV-6 infection [14] [17].

The results showed that $83.3 \%(\mathrm{n}=35)$ of children had active primary infection as indicated by positive plasma results. However, $19 \%(n=8)$ of children were positive for HHV-6 in CSF since it was the only type of sample collected from them. Active infection in these children could be confirmed if plasma sample were available and tested for HHV-6 infection. It should be noted that the patients were considered to have primary infection because of their age and that they presented with symptoms of HHV-6 infection (fever-induced seizures and rash) plus virus DNA positive by PCR.

The clinical manifestations presented in our patients with positive HHV-6 DNA were varied. The classic manifestation of HHV-6 infection was acute febrile illnesses with or without rash [4]. Our results showed that fever presented in $31 \%(\mathrm{n}=2)$ of infants and children. Other studies have also shown that acute HHV-6 can present as a febrile illness without a rash. Fever was most commonly accompanied by irritability, otitis media, upper and lower respiratory symptoms, or diarrhea [7]. Another report showed outbreaks of HHV-6 infection that presented as a febrile illness with or without rash in a number of day-care centers in Brazil [18]. Roseola, a clinical syndrome that is relatively specific for HHV-6 infection, occurred in $19 \%(\mathrm{n}=8)$ of patients in this study. However, a study by Laina et al. (2010) showed a higher percentage; $60 \%$ of HHV-6 positive infants and 
Table 1. HHV-6 PCR positive for each type of sample $(n=42)$.

\begin{tabular}{cc}
\hline Type of Sample & Number of HHV-6 PCR Positive (\%) \\
\hline Plasma & $35(83.3 \%)$ \\
CSF & $8(19 \%)$ \\
Total & 43 \\
\hline
\end{tabular}

Table 2. Clinical manifestations and syndromes associated with HHV-6 infection in 42 HHV-6 positive cases.

\begin{tabular}{cccc}
\hline Clinical Manifestations & $\mathbf{n}(\mathbf{\%})$ & Syndrome & $\mathbf{n}(\mathbf{\%})$ \\
\hline Fever & $21(50)$ & Neutropenia & $15(35.8)$ \\
Roseolainfantum & $8(19)$ & Meningitis & $3(7.1)$ \\
Seizure & $3(7.1)$ & Encephalitis & $1(2.4)$ \\
Vomiting & $2(4.8)$ & Thrombocytosis & $1(2.4)$ \\
Diarrhea & $1(2.4)$ & $\cdot$ UTI & $1(2.4)$ \\
Cough & $1(2.4)$ & Bicytopenia & $1(2.4)$ \\
Otitis media & $1(2.4)$ & Neonatal sepsis with shock & $1(2.4)$ \\
& & 'SCID & $1(2.4)$ \\
\hline
\end{tabular}

•Urinary Tract Infection; 'S Severe Combined Immunodeficiency.

Table 3. Characteristics of children with co-infection of HHV-6 DNA and other viruses.

\begin{tabular}{|c|c|c|c|c|c|c|c|c|c|}
\hline \multirow{2}{*}{$\begin{array}{c}\text { Patient } \\
\text { No. }\end{array}$} & \multicolumn{6}{|c|}{ Virus } & \multicolumn{3}{|c|}{ Associated Condition } \\
\hline & $\begin{array}{c}\text { Enterovirus } \\
\text { RNA }\end{array}$ & $\begin{array}{l}\text { Parvovirus } \\
\text { B19 DNA }\end{array}$ & $\begin{array}{c}\text { Parvovirus } \\
\text { B19 IgM }\end{array}$ & $\begin{array}{l}\text { CMV } \\
\text { DNA }\end{array}$ & Adenovirus IgM & EBV IgM & Neutropenia & $\begin{array}{c}\text { Febrile } \\
\text { Neutropenia }\end{array}$ & Meningitis \\
\hline 1 & - & + & ${ }^{\prime} \mathrm{ND}$ & - & - & + & Yes & No & No \\
\hline 2 & + & - & - & - & + & + & Yes & No & No \\
\hline 3 & - & ND & + & - & - & - & No & Yes & No \\
\hline 4 & + & - & - & - & - & - & Yes & No & No \\
\hline 5 & - & - & - & + & - & - & No & Yes & No \\
\hline 6 & + & - & - & - & - & - & No & No & Yes \\
\hline
\end{tabular}

ND: Not Done.

children with primary infection had typical roseola [3]. On the other hand, others reported roseola in a minority of cases [8].

In recent years, attention has focused on febrile seizures due to HHV-6 infection. Febrile seizures are age-dependent condition, occurring in patients aged from 6 months to 5 years old [3]. Recently, it is considered that HHV-6 plays a causative role in febrile seizures, based on the neurotropic properties of this virus and the similarity of the groups in which febrile seizures and HHV-6 infection occur [19]. Our study showed that only 7.1\% $(n=3)$ HHV-6 positive patients had febrile seizure at the time of admission to the hospital. Another study showed that among children with primary HHV-6 infection, $8 \%$ had febrile seizures, a percentage similar to the present findings [20]. However, Zerr et al. (2005) did not report any case with seizures [8]. In contrast, other studies showed higher percentage of seizures. Barone et al. (1995), for example, showed that 26\% of HHV-6 positive young children experienced febrile seizures [21]. Other symptoms, diarrhea, cough and otitis media, were also reported in HHV-6 positive infants and children, but in a lesser percentage $(2.4 \%$; $=1)$. Zerr et al. showed similar results [8].

In this study, the most frequent condition associated with HHV-6 was neutropenia, which was detected in $35.8 \%(\mathrm{n}=15)$ children. This result is in agreement with another study by Hussain et al. (2012), where they investigated the infectious causes of isolated transient neutropenia in previously healthy children. They showed that HHV-6 infection was the leading cause of transient neutropenia in previously healthy children in Kuwait [14]. A study by Karavanaki et al. (2006) showed that HHV-6 was associated with neutropenia in 2 of 24 pre- 
viously healthy children [22].

The role and frequency of HHV-6 in central nervous system (CNS) diseases of children are unclear and it is an area of ongoing investigation. A study by Ansari et al. (2004) showed that HHV-6 DNA was found in 2 of 245 CSF samples from pediatric patients with meningitis who lacked evidence of another microbiologic cause. [23]. Interestingly, we had reported three children with HHV-6 DNA in CSF and with meningitis. One of the 3 children with meningitis was positive for both HHV-6 and Enterovirus RNA in CSF sample; however, the other 2 children were positive in CSF for HHV-6 DNA, suggesting that HHV-6 was the etiologic cause of meningitis in these children. We also reported a one-year-old child and who had febrile convulsion with left side weakness and with encephalitis. This child was only positive for HHV-6 in CSF. Our result is one of few that supports the assumption that primary infection with HHV-6 in infants and children may have an important role in CNS diseases. Our data are in agreement with another study by McCullers et al. (1995), who showed that 9 out of 129 patients with focal encephalitis were infected with HHV-6 [24]. In addition, three cases of HHV-6 meningoencephalitis were reported in previously healthy children by Bozzola et al. [11]. Another study found that out of 983 cases with acute encephalopathy in Japan, $17 \%$ were caused by HHV-6. They also found that $64 \%$ of the severe cases with biphasic seizures in the study were attributed to HHV-6 and that only half of which survived without permanent neurological sequelae [25].

We found one child aged two years and 6 months who had undergone bone marrow transplant had SCID with MHC class II deficiency and graft-versus-host disease (GVHD). This child had only severe rash and was positive for HHV-6 in plasma. Unfortunately, it was difficult to define clearly whether this infection was primary or reactivation of latent infection since information on antibody seroconversion test was not available. HHV-6 reactivation is very common after bone marrow transplantation and is associated with serious transplantationrelated morbidity and mortality [26]. Out of 365 patients who underwent allogeneic hematopoietic stem cell transplantation (HSCT) tested for HHV-6, 100 experienced HHV-6 reactivation. Furthermore, 69 of these infected patients developed GVHD. The authors confirmed the association between HHV-6 and GVHD and suggested that HHV-6 might play a role in triggering severe manifestations of GVHD [27].

Six children experienced co-infection with other viruses (Table 3). One patient had triple infection with Enterovirus, Adenoviruse and EBV and another patient had dual infection with Parovirus B19 and EBV. In addition, four patients had single infection with Parvovirus B19, Enterovirus, CMV and Enterovirus, respectively. Our results are in agreement with the study of Hussain et al. (2012), which showed that neutropenia in previously healthy children in Kuwait was caused by demonstrable infection in 55\% of cases: HHV-6, 30\%; Enterovirus, 23\%; Influenza A H1N1, 13\%; Parvovirus, 10\%; EBV, 10\%; UTI by Eshcherichia coli, 7\%; Adenovirus, $7 \%$ by [14].

In conclusion, the study in Kuwait provides important information about the clinical outcome of HHV-6 infection among infants and children. Fever is the main clinical manifestation of HHV-6 infection. In addition, neutropenia is highly associated with HHV-6 infection among infants and children. Furthermore, encephalitis and meningitis are linked to HHV-6 infection in immunocompetant children, which indicate that the virus can result in different neurological complications. Finally, our results also suggest that HHV-6 may trigger the manifestations of GVHD.

\section{Acknowledgements}

The laboratory investigations were conducted at the virology unit at Faculty of Medicine, Kuwait University. The authors especially thank Dina A. Khalik and the laboratory technicians.

\section{References}

[1] Al Fawaz, T., Ng, V., Richardson, S.E., Barton, M. and Allen, U. (2014) Clinical Consequences of Human Herpesvirus-6 DNAemia in Peripheral Blood in Pediatric Liver Transplant Recipients. Pediatric Transplantation, 1, 47-51. http://dx.doi.org/10.1111/petr.12176

[2] Abdel-Haq, N.M. and Asmar, B.I. (2004) Human Herpesvirus 6 (HHV6) Infection. Indian Journal of Pediatrics, 71, 89-96. http://dx.doi.org/10.1007/BF02725664

[3] Laina, I., Syriopoulou, V.P., Daikos, G.L., Roma, E.S., et al. (2010) Febrile Seizures and Primary Human Herpesvirus 6 Infection. Pediatric Neurology, 42, 28-31. http://dx.doi.org/10.1016/j.pediatrneurol.2009.07.016

[4] Vianna, R.A., de Oliveira, S.A., Camacho, L.A., Knowles, W., et al. (2008) Role of Human Herpesvirus 6 Infection in 
Young Brazilian Children with Rash Illnesses. The Pediatric Infectious Disease Journal, 27, 533-537. http://dx.doi.org/10.1097/INF.0b013e3181673c50

[5] Tait, D.R., Ward, K.N., Brown, D.W. and Miller, E. (1996) Measles and Rubella Misdiagnosed in Infants as Exanthem Subitum (Roseola Infantum). BMJ, 312, 101. http://dx.doi.org/10.1136/bmj.312.7023.101

[6] Tremlay C. and Brady, M. (2014) Human Herpesvirus 6 Infection in Children: Clinical Manifestations; Diagnosis; and Treatment.

http://www.uptodate.com/contents/human-herpesvirus-6-infection-in-children-clinical-manifestations-diagnosis-and-tr eatment

[7] Hall, C.B., Long, C.E., Schnabel, K.C., Caserta, M.T., et al. (1994) Human Herpesvirus-6 Infection in Children-A Prospective Study of Complications and Reactivation. The New England Journal of Medicine, 18, 432-438. http://dx.doi.org/10.1056/NEJM199408183310703

[8] Zerr, D.M., Meier, A.S., Selke, S.S., Frenkel, L.M., Huang, M.L., et al. (2005) A Population-Based Study of Primary Human Herpesvirus 6 Infection. The New England Journal of Medicine, 352, 768-776. http://dx.doi.org/10.1056/NEJMoa042207

[9] Irving, W.L., Chang, J., Raymond, D.R., Dunstan, R., Grattan-Smith, P. and Cunningham, A.L. (1990) Roseola Infantum and Other Syndromes Associated with Acute HHV6 Infection. Archives of Disease in Childhood, 65, 1297-300. http://dx.doi.org/10.1136/adc.65.12.1297

[10] Rohayem, J., Dinger, J., Fischer, R., Klingel, K., Kandolf, R. and Rethwilm, A. (2001) Fatal Myocarditis Associated with Acute Parvovirus B19 and Human Herpesvirus 6 Coinfection. Journal of Clinical Microbiology, 39, 4585-4587. http://dx.doi.org/10.1128/JCM.39.12.4585-4587.2001

[11] Bozzola, E., Krzysztofiak, A., Bozzola, M., Calcaterra, V., Quondamcarlo, A., Lancella, L. and Villani, A. (2012) HHV6 Meningoencephalitis Sequelae in Previously Healthy Children. Infection, 40, 563-566. http://dx.doi.org/10.1007/s15010-012-0295-9

[12] Noguchi, T., Yoshiura, T., Hiwatashi, A., Togao, O., Yamashita, K., Nagao, E., et al. (2010) CT and MRI Findings of Human Herpesvirus 6-Associated Encephalopathy: Comparison with Findings of Herpes Simplex Virus Encephalitis. American Journal of Roentgenology, 194, 754-760. http://dx.doi.org/10.2214/AJR.09.2548

[13] Yao, K., Honarmand, S., Espinosa, A., Akhyani, N., Glaser, C. and Jacobson, S. (2009) Detection of Human Herpesvirus-6 in Cerebrospinal Fluid of Patients with Encephalitis. Annals of Neurology, 65, 257-267. http://dx.doi.org/10.1002/ana.21611

[14] Husain, E.H., Mullah-Ali, A., Al-Sharidah, S., Azab, A.F. and Adekile, A. (2012) Infectious Etiologies of Transient Neutropenia in Previously Healthy Children. Pediatric Infectious Disease Journal, 31, 575-577. http://dx.doi.org/10.1097/INF.0b013e318250084a

[15] Gautheret-Dejean, A., Manichanh, C., Thien-Ah-Koon, F., Fillet, A.M., Mangeney, N., Vidaud, M., et al. (2002) Development of a Real-Time Polymerase Chain Reaction Assay for the Diagnosis of Human Herpesvirus-6 Infection and Application to Bone Marrow Transplant Patients. Journal of Virological Methods, 100, 27-35. http://dx.doi.org/10.1016/S0166-0934(01)00390-1

[16] Dalwai, A., Ahmad, S., Pacsa, A. and Al-Nakib, W. (2009) Echovirus Type 9 Is an Important Cause of Viral Encephalitis in Infants and Young Children in Kuwait. Journal of Clinical Virology, 44, 48-51. http://dx.doi.org/10.1016/j.jcv.2008.10.007

[17] Valiaveedan, R., Rao, S., Miller, S. and Brown, A. (1987) Transient Neutropenia of Childhood. Clinical Pediatrics, 26, 639-642. http://dx.doi.org/10.1177/000992288702601204

[18] Freitas, R.B., Monteiro, T.A. and Linhares, A.C. (2000) Outbreaks of Human-Herpes Virus 6 (HHV-6) Infection in Day-Care Centers in Belém, Pará, Brazil. Revista do Instituto de Medicina Tropical de São Paulo, 42, 305. http://dx.doi.org/10.1590/S0036-46652000000600002

[19] Millichap, J.G. and Millichap, J.J. (2006) Role of Viral Infections in the Etiology of Febrile Seizures. Pediatric Neurology, 35, 165-172. http://dx.doi.org/10.1016/j.pediatrneurol.2006.06.004

[20] Asano, Y., Yoshikawa, T., Suga, S., Kobayashi, I., Nakashima, T., et al. (1994) Clinical Features of Infants with Primary Human Herpesvirus 6 Infection (Exanthem Subitum, Roseola Infantum). Pediatrics, 93, 104-108.

[21] Barone, S.R., Kaplan, M.H. and Krilov, L.R. (1995) Human Herpesvirus-6 Infection in Children with First Febrile Seizures. Journal of Pediatrics, 127, 95-97. http://dx.doi.org/10.1016/S0022-3476(95)70263-6

[22] Karavanaki, K., Polychronopoulou, S., Giannaki, M., Haliotis, F., Sider, B., Brisimitzi, M., et al. (2006) Transient and Chronic Neutropenias Detected in Children with Different Viral and Bacterial Infections. Acta Paediatrica, 95, 565-572. http://dx.doi.org/10.1080/08035250500477537

[23] Ansari, A., Li, S., Abzug, M.J. and Weinberg, A. (2004) Human Herpesviruses 6 and 7 and Central Nervous System Infection in Children. Emerging Infectious Diseases, 10, 1450-1454. http://dx.doi.org/10.3201/eid1008.030788 
[24] McCullers, J.A., Lakeman, F.D. and Whitley, R.J. (1995) Human Herpesvirus 6 Is Associated with Focal Encephalitis. Clinical Infectious Diseases, 21, 571-576. http://dx.doi.org/10.1093/clinids/21.3.571

[25] Hoshino, A., Saitoh, M., Oka, A., Okumura, A., Kubota, M., Saito, Y., et al. (2012) Epidemiology of Acute Encephalopathy in Japan, with Emphasis on the Association of Viruses and Syndromes. Brain and Development, 34, 337-343. http://dx.doi.org/10.1016/j.braindev.2011.07.012

[26] de Pagter, P.J., Schuurman, R., Visscher, H., de Vos, M., Bierings, M., van Loon, A.M., et al. (2008) Human Herpes Virus 6 Plasma DNA Positivity after Hematopoietic Stem Cell Transplantation in Children: An Important Risk Factor for Clinical Outcome. Biology of Blood and Marrow Transplant, 14, 831-839. http://dx.doi.org/10.1016/j.bbmt.2008.04.016

[27] Pichereau, C., Desseaux, K., Janin, A., Scieux, C., de Latour, R.P., Xhaard, A., et al. (2012) The Complex Relationship between Human Herpesvirus 6 and Acute Graft-versus-Host Disease. Biology of Blood and Marrow Transplant, 18, 141-144. http://dx.doi.org/10.1016/j.bbmt.2011.07.018 
Scientific Research Publishing (SCIRP) is one of the largest Open Access journal publishers. It is currently publishing more than 200 open access, online, peer-reviewed journals covering a wide range of academic disciplines. SCIRP serves the worldwide academic communities and contributes to the progress and application of science with its publication.

Other selected journals from SCIRP are listed as below. Submit your manuscript to us via either submit@scirp.org or Online Submission Portal.
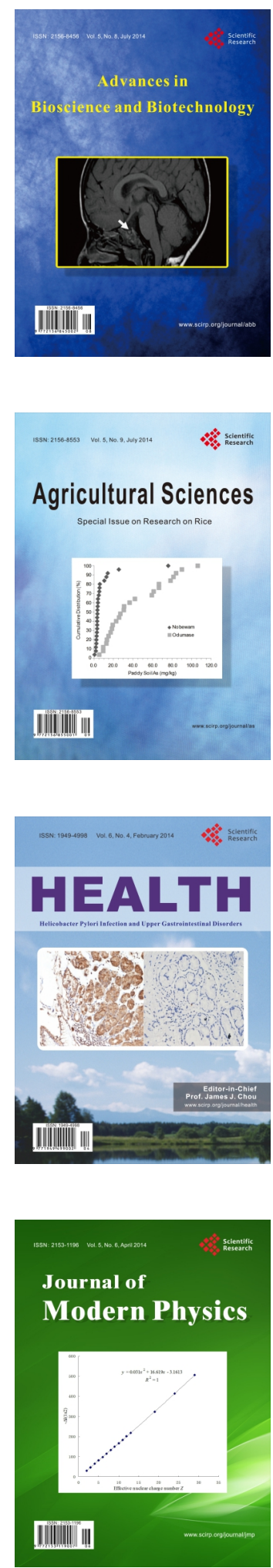
